\title{
Familial paroxysmal dystonia induced by exercise
}

\author{
GT PLANT, * AC WILLIAMS, † CJ EARL, CD MARSDEN \\ From the National Hospital for Nervous Diseases, Queen Square, and the Department of Neurology, Institute \\ of Psychiatry, King's College Hospital, London, UK
}

SUMMARY A mother and daughter are described with paroxysmal dystonia induced by exercise. As has been reported in one previous family, the attacks were provoked in the lower limbs by prolonged exertion but not by sudden movements. It was also found that involuntary movements could be induced focally in any limb either by local exercise or by sensory stimulation restricted to that limb.

We report a disorder occurring in a mother and daughter which we consider to be the second example of familial paroxysmal dystonia induced by exercise. This condition is related to the familial paroxysmal choreoathetosis of Mount and Reback ${ }^{1}$ (subsequently named familial paroxysmal dystonic choreoathetosis by Lance $^{2}$ ), but differs in that attacks are precipitated by exertion and are briefer. That this might be a separate nosological entity was suggested by Lance ${ }^{2}$ when reporting the other family. Apart from illustrating that Lance's family is not unique, the purpose of this paper is to record the additional clinical features of the induction of focal attacks by local exercise or by sensory stimulation, and a normal electroencephalogram during such attacks.

\section{Case reports}

\section{Case One}

A 34-year-old right-handed housewife (II 3 in fig 1) was referred to the National Hospital, Queen Square, for evaluation of paroxysmal involuntary movements of the limbs. From the age of two the family recalled that she had been reluctant to walk long distances but the earliest attack occurred at the age of eight. From then until the date of referral a consistent pattern became established in that if she walked continuously for a quarter of a mile walking would become difficult, and eventually impossible, because of involuntary movements of her legs. She described at first a sensation as if elastic bands were attached to her knees, drawing them up towards her stomach. She would then be

*Present address and address for reprint requests: Kenneth Craik Laboratory, Department of Physiology, Cambridge, UK.

†Present address: Department of Neurology, Queen Elizabeth Hospital, Birmingham, UK.

Received 12 April 1983. Accepted 20 June 1983 forced to stop walking, would lie on the ground, and writhing movements of the legs continue for ten to fifteen minutes. It was unusual for the upper limbs to be conspicuously involved in these attacks but, perhaps a half a dozen times in her life, she had had generalised attacks involving all four limbs. These had occurred under similar circumstances but with the addition of severe anxiety or other emotional stress. There had never been impairment of consciousness in the attacks. Sudden movement, startle, alcohol and coffee had never induced an attack. There was no sensory aura, and she could not abort attacks once they had begun. There had been no diurnal variation in the likelihood of attacks to occur.

Witnessed attacks were provoked by ascending five flights of stairs or by exercise cycling for four minutes (fig 2). The lower limbs were affected equally, the feet would invert repeatedly with extension of the great toes and flexion at the hip and the knee. Such attacks would always persist for between five and fifteen minutes.

Involuntary movements of the right upper limb were first witnessed when the patient was asked to write continuously to dictation. As she commenced a second sheet of

I

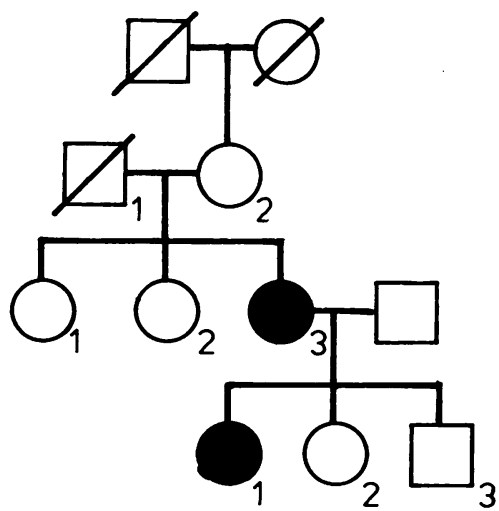

Fig 1 Pedigree of Cases 1 (II 3) and 2 (III 1). 


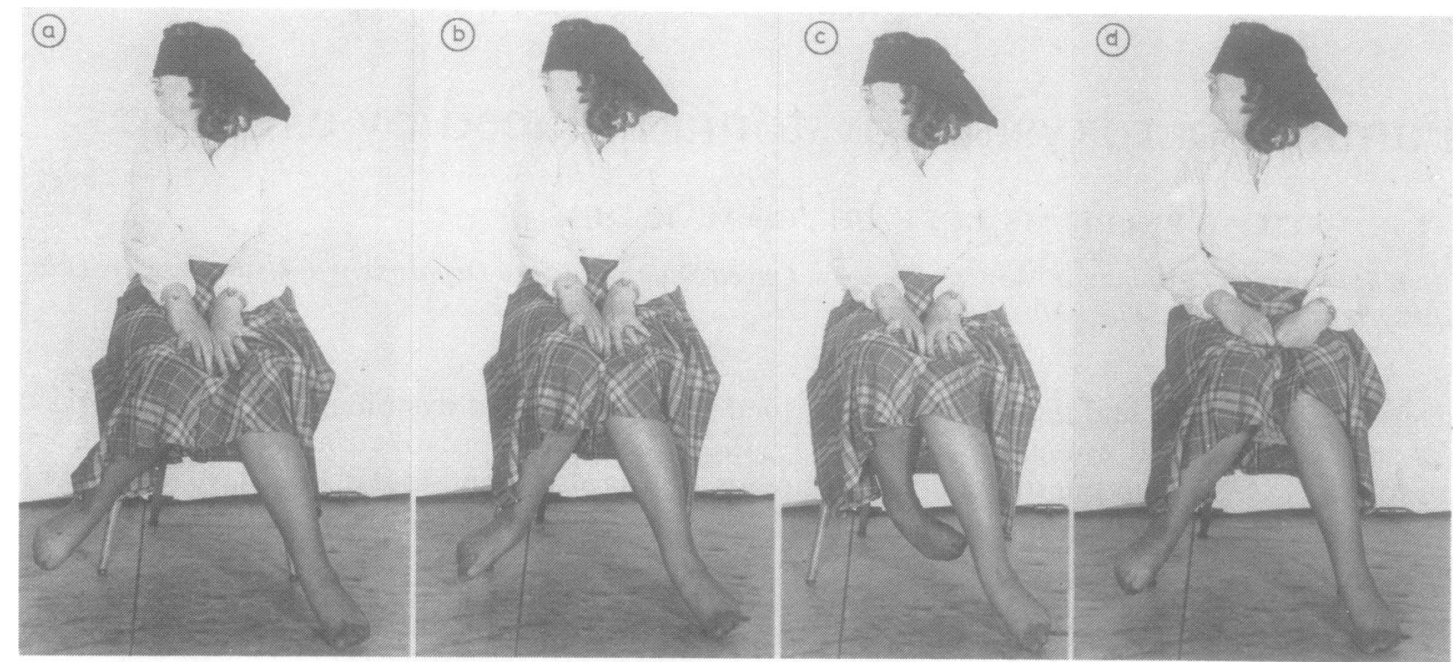

Fig 2 Involuntary movements of both lower limbs are shown occurring after prolonged exertion, in this case ascending five flights of stairs. Such movements would continue for approximately ten minutes.

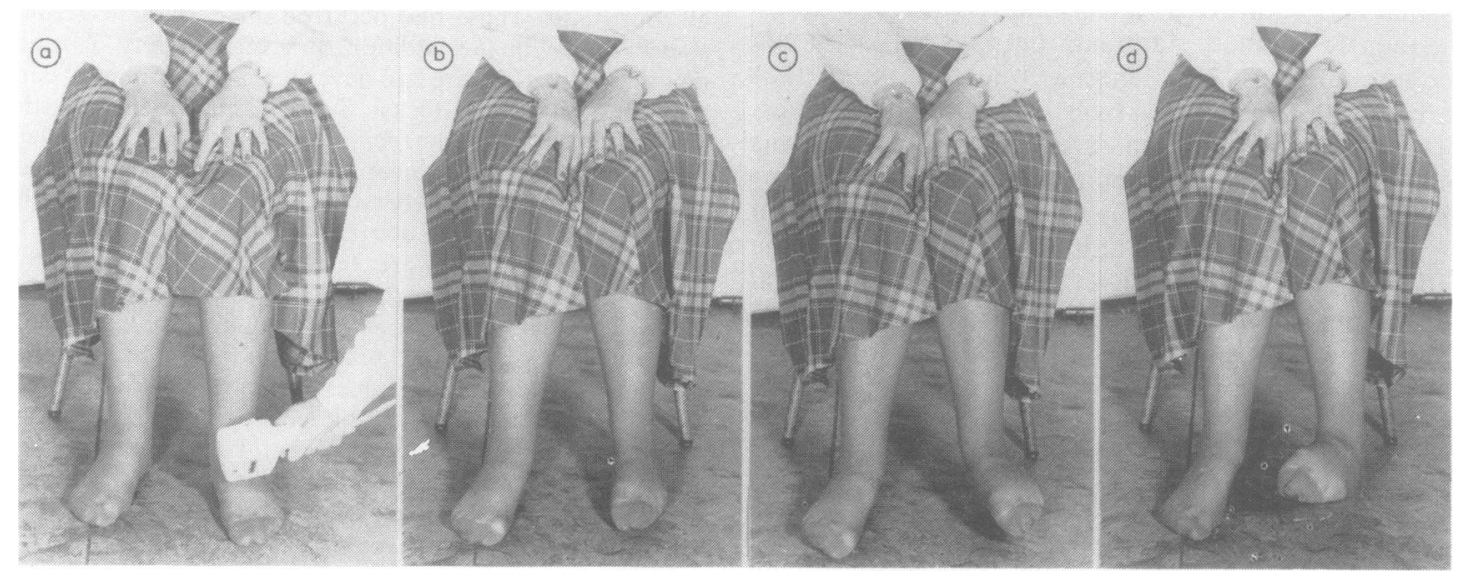

Fig 3 Involuntary movements of the left leg provoked by sensory stimulation, in this case the application of a vibrator to the left ankle. Dystonia induced in this way occurred with a shorter latency than dystonia following exertion and also tended to be of shorter duration.

paper the fingers of the right hand began alternately flexing and extending. Control of the pen became impossible as the arm adducted at the shoulder and flexed at the wrist. At the same time the right foot adopted a dystonic posture. Exercising either upper limb using a small hand-held exercising device would provoke attacks in the limb exercised, those on the right being more severe and involving more obviously the ipsilateral lower limb. Upper limb attacks were of shorter duration than those in lower limbs, usually four or five minutes.

It was found that similar focal attacks could be precipitated reliably, perhaps more easily, and certainly with a shorter latency, by a variety of stimuli other than exercise.
Passive movements of a limb, continued for $30-60 \mathrm{sec}-$ onds, would induce focal attacks identical to those described above. There tended to be some spread of the involuntary movements and dystonic postures to the ipsilateral arm or leg. The application of a Pifco vibrator to a limb produced involuntary movements within a few seconds (fig 3 and 4); stimulation of a muscle tendon or a bony point seemed equally effective. Other successful stimuli were rendering an arm ischaemic by means of a tourniquet, or the delivery of a brief electric shock by means of finger electrodes. The application of a vibrator to the forehead provoked blepharospasm, and to the sternum caused dystonic movements and posturing of the trunk. 


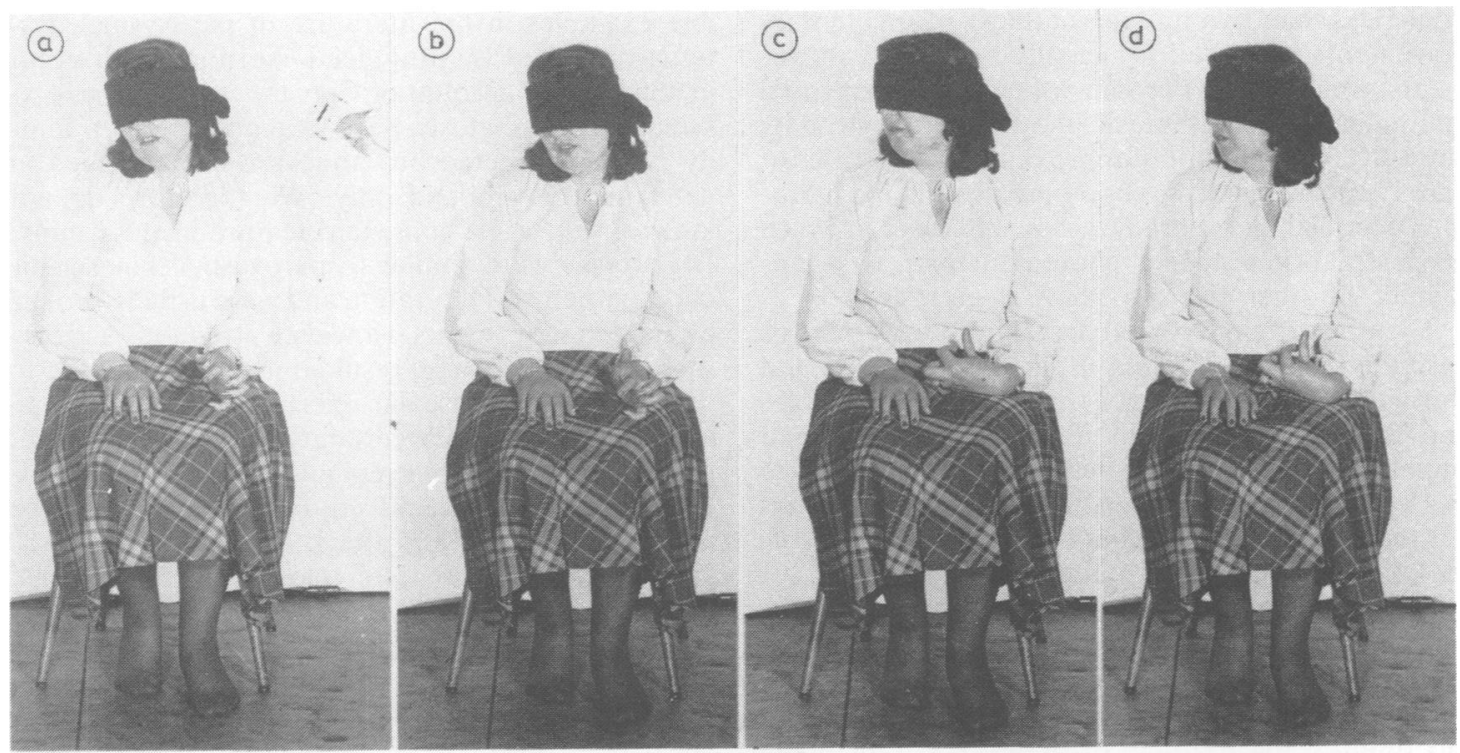

Fig 4 Following the application of a vibrator to the left forearm involuntary movements are shown which are limited to the left upper limb.

The family tree of this patient (II 3 ) is shown in fig 1. Nothing is known of the proband's father's family. He was born in Scotland and was said to have had an infantile hemiparesis but there is no recollection of his having been subject to attacks of any kind. The proband's mother is said to have the Sturge-Weber syndrome, but has not been examined by us. There is no recollection that she or any members of her family are subject to attacks of any kind. Her family is well documented as many of them have originated from the same small Cheshire village for several generations. The patient's husband has epilepsy and one of their children (III 2) is subject to partial complex seizures for which he takes carbamazepine.

General and neurological examination revealed no abnormalities. Routine blood count and biochemistry including copper studies, were within normal limits, and slit lamp examination for Kayser-Fleischer rings was negative. Skull radiographs, CT scan and a resting EEG were within normal limits. During an attack plasma electrolytes, calcium, magnesium and glucose were normal and an EEG was not considered to show any significant change from the resting record. For ten years before her referral the patient had taken phenobarbitone. This had not noticeably affected the frequency or severity of her attacks, which had become more troublesome over the years. Levodopa in a small dose (levodopa $100 \mathrm{mg}$ with carbidopa $10 \mathrm{mg}$ four times daily) also had no effect. Treatment with clonazepam may have been effective in diminishing the likelihood of attacks to occur but the effect was slight.

\section{Case Two}

The 14-year-old daughter of Case One (III 1) has been seen and examined. She is, as yet, the only other member of the family known to be affected.
From the age of three, it was recalled, it was her wont to ask to be carried on long walks, giving as her reason for this the development of a "legs headache". It was not until the age of eleven, however, that attacks similar to those experienced by her mother were observed. They tended to occur after rather more prolonged exertion. One situation in which an attack would invariably happen was if, following a physical education class, she was required to ascend two or three flights of stairs to the next lesson.

In hospital an attack was induced by a prolonged session in the gymnasium. She developed similar involuntary movements to those described in Case One, with the exception that the characteristic posture of her feet was plantar flexion, rather than inversion, and dystonic posturing of the trunk and upper limbs were more prominent. The attack lasted for twenty minutes and she found it easier to continue walking during the attack than did her mother. Although provoking attacks by exertion was more difficult than in her mother it was found almost as easy to induce focal attacks by passive movements and by vibration. Other stimuli mentioned in Case One were not attempted.

Clinical examination was again negative as were laboratory investigations. The patient is taking clonazepam and considers that her attacks are less likely to occur but they have certainly not been abolished.

\section{Discussion}

Mount and Reback ${ }^{1}$ first described a family in whom prolonged attacks of choreoathetosis were triggered by alcohol or anxiety. Richards and Barnett ${ }^{3}$ suggested that this should be distinguished from the 
brief (less than two minutes) attacks of involuntary movements provoked principally by sudden movements which have become known as paroxysmal kinesigenic choreoathetosis, the term introduced by Kertesz. ${ }^{4}$ There are now approximately 100 cases of paroxysmal kinesigenic choreoathetosis in the literature. Familial and sporadic cases, and cases in which paroxysmal kinesigenic choreoathetosis is symptomatic of other disorders, have been reported.

The cases of paroxysmal dystonic choreoathetosis described by Mount and Reback, ${ }^{1}$ Richards and Barnett, ${ }^{3}$ Forssman, ${ }^{5}$ Lance (first pedigree), ${ }^{2}$ Tibbles and Barnes, ${ }^{6}$ and Mayeux and Fahn ${ }^{7}$ all have had similar attacks. Detailed descriptions are available in 18 patients in six families. The most common trigger factors have been alcohol and anxiety, with coffee, fatigue and the spontaneous occurrence of attacks being mentioned in a few examples. Attacks have lasted at least five minutes and up to four hours. Phenytoin and phenobarbitone have not been effective in controlling the attacks but clonazepam has reduced the frequency of episodes in members of the two families to whom it has been given. ${ }^{26}$

Lance $^{2}$ recognised that his second pedigree was distinct from the cases mentioned above. The attacks were intermediate in duration between those of paroxysmal kinesigenic choreoathetosis and those of paroxysmal dystonic choreoathetosis. They lasted between five and thirty minutes, and they were precipitated by prolonged exertion. The family we have reported is suffering from a very similar disorder. Apart from the attacks themselves there are two other points worthy of mention. Firstly the response to clonazepam was disappointing..Secondly the family trees of both families are compatible with an autosomal dominant mode of inheritance with incomplete penetrance.

In the other cases of familial paroxysmal dystonic choreoathetosis inheritance has been as an autosomal dominant. Mount and Reback suggested non sex-linked recessive transmission in their family but, as has been pointed out elsewhere, their published family tree is in keeping with autosomal dominant transmission. In the family reported recently by Mayeux and Fahn ${ }^{7}$ two brothers had typical attacks of prolonged paroxysmal dystonia, there was a family history of dominantly inherited cerebellar ataxia, but not of dystonia. Whatever the relationship between the two disorders in this family, the paroxysmal dystonia may have been inherited in a recessive manner, or by incomplete penetrance of a dominant gene. In Forssman's family, ${ }^{5}$ the best documented from the point of view of inheritance, it occasionally happened that a gene carrier was not himself afflicted by any symptoms.

There are, to our knowledge, only two other poss- ible examples in the literature of paroxysmal dystonia provoked by prolonged exertion. Both occur

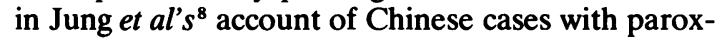
ysmal choreoathetosis. Seven members of their family $A$ were affected but attacks were described in detail in the proband only. We therefore do not know if this was a consistent feature in this family. His attacks were similar to paroxysmal kinesigenic choreoathetosis in duration and were usually evoked by sudden movements. However, strenuous activity, such as arm wrestling, resulted in attacks limited to the side of the muscular exertion. It is difficult to classify this case with certainty. He had coincident generalised tonic-clonic epilepsy, as did other members of his family, and an EEG was said to be abnormal during an attack of choreoathetosis. Jung's "sporadic case one" is similarly most unusual in that the attacks, although also like those of paroxysmal kinesigenic choreoathetosis, were never precipitated by sudden movement but by strenuous activity and also being "tense, embarrassed or startled".

With regard to the focal manifestations reported in the present family, focal aspects of paroxysmal kinesigenic choreoathetosis have been reviewed elsewhere by one of us. ${ }^{9}$ Of the 18 patients with prolonged attacks of paroxysmal dystonic choreoathetosis in which detailed descriptions are available, nine had exclusively bilateral attacks, and in the other nine unilateral attacks occurred on either side and were associated with rare bilateral attacks. Within families it appears that unilateral and bilateral attacks coexist but one dominates. In no case has it been stated that an attempt has been made to induce an attack by passive movement or sensory stimuli such as those employed in the present family. The movements of the upper limbs, as part of a generalised attack, described in detail in Mount and Reback's patient were very similar in nature to the focally induced arm attacks described in our Case One. In one member of his second pedigree, Lance ${ }^{1}$ states that attacks could be brought on by forms of exercise other than walking such as polishing floors, but also states that the patient had never been aware of her arms being involved in the attacks. Our patient was only vaguely aware that attacks might occasionally involve the upper limbs, and it seemed to us that she successfully avoided attacks by "pacing" herself in all her activities. She was most likely to be "caught out" when walking with others. Lance does not report attempts to provoke attacks by passive movements or sensory stimulation.

The aetiology of this fascinating group of movement disorders is unknown. That they are due to a disorder of basal ganglia function akin to dystonia 
Table Comparison of three familial paroxysmal dystonias

\begin{tabular}{|c|c|c|c|}
\hline Feature & $\begin{array}{l}\text { Paroxysmal kinesigenic } \\
\text { choreoathetosis }\end{array}$ & $\begin{array}{l}\text { Paroxysmal dystonia } \\
\text { induced by exercise }\end{array}$ & $\begin{array}{l}\text { Paroxysmal dystonic } \\
\text { choreoathetosis }\end{array}$ \\
\hline $\begin{array}{l}\text { Inheritance } \\
\text { Male:female ratio } \\
\text { Age of onset (yr) } \\
\text { Attacks: Frequency } \\
\text { Duration } \\
\text { Trigger }\end{array}$ & $\begin{array}{l}\text { Dominant or sporadic } \\
4: 1 \\
1-33 \\
100 / \text { day-1/month } \\
5 \text { min } \\
\text { Sudden movement or } \\
\text { startle }\end{array}$ & $\begin{array}{l}\text { Dominant } \\
1: 4 \\
3-20 \\
1 / \text { day }-2 / \text { month } \\
5-30 \text { min } \\
\text { Continued exercise or } \\
\text { sensory stimuli }\end{array}$ & $\begin{array}{l}\text { Dominant } \\
2: 1 \\
1-22 \\
3 / \text { day-2/yr } \\
2 \text { min-4 hr } \\
\text { Nil }\end{array}$ \\
\hline Precipitant & Stress & Stress & $\begin{array}{l}\text { Alcohol, coffee, } \\
\text { fatigue, stress }\end{array}$ \\
\hline Treatment & Anticonvulsants & $?$ & Clonazepam \\
\hline
\end{tabular}

due to other causes has been inferred from the character of the involuntary movements observed and the lack of significant EEG abnormalities during and between attacks. Is it possible to draw any closer parallels between the paroxysmal and other dystonias in the light of the cases reported above?

Focal dystonic syndromes as the presentation of generalised idiopathic torsion dystonia, and as isolated dystonias, are well recognised. ${ }^{10}$ In this respect our family is of interest because it was possible to demonstrate a number of dystonic manifestations in a single patient, including blepharospasm and, perhaps, an exaggerated form of writer's cramp. The precipitation or exacerbation of dystonia by movement (action dystonia) is commonly seen in the early stages of idiopathic and symptomatic torsion dystonia, and in levodopa induced dyskinesias. However, movement in these conditions merely causes the limb to adopt a dystonic posture; it does not provoke attacks resembling kinesigenic choreoathetosis or the other paroxysmal dystonias.

Exercise plays an important role in hereditary progressive dystonia with marked diurnal fluctuation described by Segawa and his colleagues. ${ }^{11}$ The condition commences insidiously in childhood with dystonic postures and movements occurring after exercise or as the day progresses. The legs particularly are affected. Sleep gives relief and levodopa dramatically prevents the condition. The illness is familial but the pattern of inheritance is not constant. Dystonia with diurnal fluctuation resembles the illness described here in that exercise is the precipitating factor. However, it differs in that the dystonia so produced appears gradually and persists until the patient rests. There is no florid attack as witnessed in our family and as described by Lance. ${ }^{2}$

We conclude that Lance's second pedigree ${ }^{1}$ and our family have a unique disorder which may be described as familial paroxysmal dystonia induced by exercise. The distinction of this condition from other familial paroxysmal dystonias is summarised in the table. The observation that passive as well as active movement can provoke focal dystonia in this disorder suggests that a proprioceptive trigger may precipitate a somatotopically localised neuronal abnormality, presumably within the basal ganglia. How this occurs is unknown.

\section{References}

'Mount LA, Reback S. Familial paroxysmal choreoathetosis. Arch Neurol Psychiat (Chicago) 1940;44:841-7.

${ }^{2}$ Lance JW. Familial paroxysmal dystonic choreoathetosis and its differentiation from related syndromes. Ann Neurol 1977;2:285-293.

${ }^{3}$ Richards RN, Barnett HJM. Paroxysmal dystonic choreoathetosis: a family study and a review of the literature. Neurology (Minneap) 1968;18:461-9.

${ }^{4}$ Kertesz A. Paroxysmal kinesigenic choreoathetosis. Neurology (Minneap) 1967;17:680-90.

${ }^{5}$ Forssman $H$. Hereditary disorder characterized by attacks of muscular contractions, induced by alcohol amongst other factors. Acta Med Scand 1961;170:517-33.

- Tibbles JAR, Barnes SE. Paroxysmal dystonic choreoathetosis of Mount and Reback. Pediatrics 1980;65:149-51.

${ }^{7}$ Mayeux R, Fahn S. Paroxysmal dystonic choreoathetosis in a patient with familial ataxia. Neurology (Minneap) 1982;32:1184-86.

${ }^{8}$ Jung S, Chen K, Brody J. Paroxysmal choreoathetosis: report of Chinese cases. Neurology (Minneap) 1973;23:749-55.

${ }^{9}$ Plant GT. Focal paroxysmal kinesigenic choreoathetosis. J Neurol Neurosurg Psychiatry 1983;46:345-8.

${ }^{10}$ Marsden CD. Dystonia: the spectrum of the disease. Res Publ Assoc Res Nerv Ment Dis 1976;55:351-70.

"Segawa M, Hosaka A, Miyawaga F, Nomura Y, Imai H. Hereditary progressive dystonia with marked diurnal fluctuation. Adv Neurol 1976;14:215-33. 